\title{
Methods of assessing reading used by Iranian EFL teachers
}

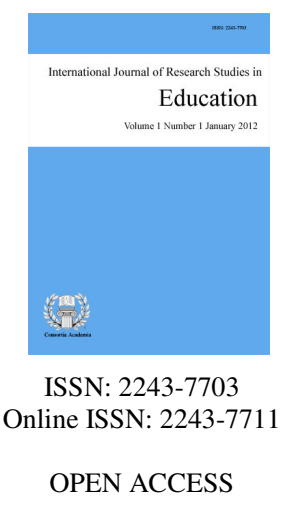

Ketabi, Somaye $\varangle$

Department of Foreign Languages, University of Isfahan, Iran (samk1989.sk@ gmail.com)

\section{Abstract}

Investigating the effects of different methods of assessing reading on students' reading comprehension has been one of the major topics among Iranian EFL researchers (Atai \& Nikuinezhad, 2006; Delgoshaei, Kharrazi, \& Talkhabi, 2011; Shams \& Tavakoli, 2014). However, the amount of popularity of these methods among teachers has not gained this much attention. The present study examined the popularity of different methods of assessing reading among teachers of adult and young adult learners and also investigated the difference in the frequency of the methods used by these two groups of teachers. Categories of different methods were chosen based on Brown's (2004) taxonomy and the study conducted by Cheng, Rogers, and Hu (2004). Background Information Questionnaire and assessment questionnaire were used to collect the data. The results revealed that Iranian teachers did not use a variety of reading assessment methods in their classes. The most common method to assess reading among Iranian teachers was reported to be reading aloud, and other methods of assessing reading - e.g. preparing summaries and oral questioning - were far less common than reading aloud. Alternative methods of assessment - e.g. journals and portfolios - were the least common methods as were reported by Iranian EFL teachers.

Keywords: English as Foreign Language; assessment; alternative assessment; reading; reading assessment methods 


\section{Methods of assessing reading used by Iranian EFL teachers}

\section{Introduction}

\subsection{Reading comprehension}

Reading can be the most important skill in academic contexts for second/foreign language learners (Grabe, 1991). This importance can also be the result of large standardized testing procedures which have been implemented since the establishment of literacy standards in the United States and Canada (Ediger as cited in Celce-Murcia, 2001). Another factor which has increased this emphasis is the language input which is acquired through reading by the use of various sources of portable reading materials (Ibid). Given the importance of reading and its contribution in building learners' language proficiency, standardized formal tests have been developed for decades and many studies have focused on these tests. Traditional published standardized tests are still in vogue in spite of the advent of performance-based assessment and the move towards formative assessment (Coles, 1998). Reading comprehension is complex and cannot be assessed through tests and simple scores. This complexity is mostly because of the fact that reading is an interactive socio-linguistic process that not only deals with the text but also involves the reader and the social context (Bernhardt, 1991). According to Grabe (1991), six general skills and knowledge areas are active in the reading process:

Automatic recognition skills

$>\quad$ Vocabulary and structural knowledge

$>$ Formal discourse structure knowledge

$>$ Content/world background knowledge

$>\quad$ Synthesis and evaluation skills/strategies

$>\quad$ Metacognitive knowledge and skills monitoring

Aside from the skills contributing to reading comprehension, there are different genres or types of written texts which have some special rules of their own. Readers' effective comprehending of different texts depends on understanding these rules and conventions. According to Brown (2004) common genres are:

$>$ Academic reading - General interest articles, technical reports, reference material, essays and theses.

$>\quad$ Job-related reading - Messages, reports, schedules, applications, questionnaires, forms and financial documents.

$>$ Personal reading - Newspaper and magazine, letters, emails, recipes, menus, novels, short stories, comic strips.

So, by considering the lists of the skills and genres (and other lists of the components which play a role in reading comprehension), one can easily understand that reading in a second or foreign language is definitely a demanding job for students and so is the assessment of this skill for teachers.

\subsection{Reading typology and the related assessment issues}

Different types of reading tasks should be first identified before assessing this skill. A comprehensive taxonomy was suggested by Brown (2004). 
$>$ Perceptive reading: In perceptive reading the reader turns attention to letters, forms, and punctuation. Bottom-up processing is involved in this type of reading.

> Selective reading: A level beyond perceptive reading is selective reading in which comprehension of lexical and grammatical features in a short stretch of language is in focus. Bottom-up and top-down processes may be used in selective reading.

Interactive reading: Reading long stretches of language (from one paragraph to several pages) which involves sociolinguistic interaction with the text is called interactive reading. Reading short stories, descriptions, recipes, and directions are some tasks which involve interactive reading. Top-down processing is used more than bottom-up processing in this type of reading.

Dxtensive reading: Long pieces of writing such as novels, long articles, and technical reports are some of the materials employed in extensive reading. Global understanding of the text is in focus in this type of reading. When readers are involved in extensive reading, they usually make use of top-down processing.

Defining reading assessment tasks based on four types of reading will give teachers a clear image of assessment tasks. Each of the four types of reading and their relevant assessment considerations are discussed in detail in the following.

\section{Perceptive reading tasks}

Literacy tasks -i.e. tasks assigned at early stages of reading and writing- are building blocks for further stages of learners' development. These tasks usually include alphabets, words, and sentence recognition and can be carried out by the use of reading aloud, written responses, multiple-choice items, and picture-cued items (Brown, 2004). In reading aloud tasks, the students should read the letters, words, or short sentences. Written response tasks are somehow the same as reading aloud, but the students should reproduce the stimuli in written form. Evaluation of learners' performance, however, should be conducted with care, as the source of the error might be in the writing or the reading skill of the learners.

\section{Selective reading tasks}

Just at one level above the first stage in becoming literate, learners are engaged in tasks focused on formal aspects of language (i.e. vocabulary and grammar). In contrast to what most of teachers think of selective reading tasks, they are not designed to assess students' lexical and grammatical knowledge (Brown, 2004). "Lexical and grammatical aspects of language are simply the forms we use to perform all four of the skills of listening, speaking, reading, and writing" (Ibid: p. 194). Some selective reading tasks are multiple-choice items, maching items, editing, picture-cued questions, and gap-filling items.

Multiple-choice items range from decontextualized grammar/vocabulary-focused to contextualized cloze tasks. A modified version of this task is multiple-choice cloze task. The context which is provided in this task helps the learner find the general set of vocabulary/grammatical rules which s/he should refer to.

> Matching items can be simple tasks of matching meanings or contextualized pragmatic tasks.

Dditing is a well-recognized test which has been used in TOEFL and other standardized proficiency tests, too. Students see a sentence with one grammatical error, and then they should find the error.

> Picture-cued tasks in selective category are of two kinds: (a) multiple-choice picture-cued response, and (b) diagram-labeling tasks. In the first type, students read a description and then choose the related picture. In the second type, different parts of a picture or diagram are described, and the students should assign each description to the related picture. 
Ketabi, S.

$>$ Multiple-choice and matching items can be converted into gap-filling tasks in which the students should write the correct answer (Brown, 2004). However, validity of gap-filling tasks is under question, since the source of the errors can be the writing or the reading skill.

\section{Interactive reading tasks}

Meaning is more important than form in interactive reading; therefore, top-down processing is involved in this type of reading. Cloze tasks, impromptu reading followed by comprehension questions, short-answer tasks, editing long texts, ordering, and information transfer (reading charts, maps, or graphs) are some possible interactive reading tasks (Brown, 2004). Cloze task is a popular task designed by deleting every $n$th word ( $n$ is usually a number between 5 and 12) in a text of one or two paragraphs. One or two sentences are not changed in order to provide context (Alderson, 2005). Oller (1979) argues that cloze tasks are integrative tasks which measure all language abilities. Teachers usually use two approaches to score cloze tests: exact word or appropriate word approach. In the former the only correct answer is the exact word which is omitted, but in the latter any word which is meaningful in the text in correct.

In impromptu reading task, students read a text and immediately answer some questions (written or oral) about the topic, phrases and idioms in the text, grammatical features and the like. This is one of the oldest techniques to assess reading comprehension. In short-answer tasks, students are asked some questions which require short responses. Their responses can be used to see whether students have correctly comprehended the text or not (Alderson, 2005). In ordering tasks, learners are presented a scrambled set of sentences or paragraphs which they have to unscramble. However, test designers should be careful in choosing the texts and provide texts which have just one possible order of paragraphs or sentences (Alderson, Clapham, \& Wall, 1995). Information transfer tasks are associated with graphic texts (tables or charts). Students should identify the required information in the tables, charts maps, etc. and answer the questions (Alderson, 2005).

\section{Extensive reading tasks}

Extensive reading includes longer texts than those in perceptive, selective, and interactive reading. Technical reports, stories, and long essays are in the extensive reading category (Brown, 2004). Summarizing, note taking, and outlining are some tasks that can be employed to assess extensive reading. As its name suggests, summarizing task includes students' reading a text and providing a summary of the main ideas or some parts of the text (Alderson, 2005). Students' comprehension of the text can also be assessed by the use of note-taking and outlining tasks. Students' ability to present key information or organized outline of the text shows effectiveness of reading strategies they have used (Brown, 2004). Day and Park (2005) presented a framework to develop reading questions and to analyze instructional materials. They considered different types of comprehensions (literal, reorganization, inference, prediction, evaluation, personal, and response) and different forms of questions (yes/no, alternative, true/false, wh-questions, and multiple choice) as two important factors in developing their framework. In Day and Park's framework (2005), literal comprehension refers to understanding facts, dates, times, and other explicitly stated information in the text. Questions which require this type of comprehension can be answered directly by reading the text.

Day and Park believe that teachers first check their students' understanding of the reading by asking literal comprehension questions. Reorganization is the second type of comprehension in this framework which is refers to getting information from various parts of the text and mixing them in order to reach additional understanding and global view of the text. The third type of comprehension is inference in Day and Park's taxonomy which needs not only the materials directly stated in the text, but also learners' own knowledge. The other type of comprehension which needs learners' knowledge is prediction which requires readers to predict what will happen next. Evaluation and personal response are other types of comprehension in Day and Park's framework which require the learners to present a judgment about the text and response to the text with their own feelings respectively. 
The researcher in the present study found Brown's (2004) taxonomy more related and comprehensive than other frameworks and taxonomies. Therefore, different tasks of assessing reading are grouped based on Brown's classification in the present study.

\subsection{Alternative assessment methods}

Alternative assessment methods are not focused on produced results; instead they are aimed at created results. In other words, they are performance-based and designed to improve communication as a meaningful activity. They are mostly used in learner-centered classes and help students to reflect on their learning process and assess their own development. Therefore, unlike traditional methods of assessment (e.g. achievement tests) evaluating students is not limited to teachers and involves students as well. The focus of alternative assessment is more on students' strengths rather than their weaknesses, so the process of grading is different from what is common in traditional testing. The advent of the concept of communicative competence increased the necessity of performance-based and authentic assessment. It is thoroughly different from what is common in traditional testing in which limited and artificial examples of language are presented to students.

Gipps (1995) categorized alternative assessment methods based on who played the main role in the assessment process. Some tasks are accomplished by learners; e.g. portfolios, journals, and self-assessment. These tasks involve students in planning and completing projects based on some stages. Process and products are equally important in these tasks. Portfolios are collections of students' performances (oral, written, etc.) which are not compared with other students' works, and students do not experience the anxiety which is present in traditional paper-and-pencil tests. A journal is defined as 'a log (or 'account') of one's thoughts, feelings, reactions, assessments, ideas, or progress toward goals, usually written with little attention to structure, form, or correctness" (Brown, 2004, p. 260). Classroom journals consist of written dialogues between students and teachers in which teachers comment on students' learning process. There are also some tasks which are conducted by people other than students; i.e. peers or teachers. Some examples of these tasks are peer-assessment and observations.

\subsection{Classroom assessment}

Instructors of English as a second/foreign language in Canada, Beijing, and Hong Kong were examined for their beliefs about language assessment and evaluation in Cheng, Rogers, \& Hu's study (2004). They were examined by the use of 32 questionnaire items. Three parts of this questionnaire were about major assessment and evaluation activities such as purposes of assessment, assessment methods (used in assessing students' reading, writing, speaking, and listening skills) and assessment procedures (different kinds of feedback used, time devoted to assessment, and sources of assessment questions). The results revealed some similarities as well as contradictories and the researchers claimed that the contradictories were because of different settings, number of students in each class, experience of the teachers, and many other teacher/learner-related factors.

\subsection{Assessing reading in Iranian EFL classes}

Studies about methods of assessing reading in Iran are mostly limited to some specific methods and their effects on improving students' reading comprehension. Jalalifarahania and Ghovehnodoushan (2013) were found to be the first researchers who studied preferred reading assessment methods and the amount of feedback provided by Iranian teachers. In their survey, Jalalifarahania and Ghovehnodoushan distributed questionnaires among 40 Iranian EFL teachers. The questionnaire consisted of 12 questions and a 5-point scale was provided for them. However, the researchers did not use a framework for methods of assessing reading, nor did they mention any specific methods of assessing reading. In general, they found that teachers considered the useful information in formative assessment very little, believed in oral tests more than written forms, and accepted their roles as providers of feedback.

In Atai and Nikuinezhad (2006), the effects of portfolio assessment on metacognitive reading strategy 
awareness of senior high school Iranian students were studied. Students' motivation for reading via portfolios and their attitudes towards portfolio assessment were also investigated. It was found that over 85 percent of students preferred portfolios and noted that portfolios helped them in self-assessment and recognizing their strengths and weaknesses. The students also commented that the time needed to complete portfolios and the load of tasks was demanding. The reason, as Atai and Nikuinezhad mentioned, could be the fact that these students were accustomed to traditional methods of assessing and had never been assessed by portfolios before.

Portfolio assessment method was the focus in Delgoshaei, Kharrazi, and Talkhabi (2011) study, too. They found that portfolios were effective in improving students' motivation in reading, and they could help students more than traditional methods of assessing reading. In another study, Akhondi and Aziz Malayeri (2011) investigated differences of three methods of assessing reading; i.e. incomplete outline, graphic organizer, and summary writing. They found that graphic organizer was the most difficult task, and writing the outline was the easiest. The effects of peer/self-assessment and traditional tests on Iranian learners' reading comprehension were investigated by Shams and Tavakoli (2014). They concluded that peer-assessed students outperformed those learners who used self-assessment and traditional assessment. Moreover, Naeimi (2015) compared the effects of two dynamic assessment approaches on the reading comprehension of Iranian EFL learners and found that these approaches could be more effective in improving students' reading skills than traditional assessment approaches.

\subsection{Overview of the present study}

Although the effect of alternatives in assessment has been the focus among Iranian researchers of EFL studies, other methods of assessing reading have not been this much popular. Therefore, the researcher in this study aimed at investigating the most popular methods of assessing reading used by Iranian EFL teachers. Two groups of teachers (teachers of adult and young adult learners) were chosen to obtain more comprehensive results and also compare the methods based on the difference in learners' age.

\section{Methodology}

\subsection{Research questions and hypotheses}

This study was conducted to find answers to the following questions:

$>\quad$ What are the most popular methods of assessing reading among Iranian EFL teachers of adult and young adult learners?

$>\quad$ Are there any differences between methods of assessing reading used by Iranian EFL teachers of adult and young adult learners?

\subsection{Instruments}

Two questionnaires were employed to collect the data for this study: Background Information Questionnaire (BIQ) and assessment questionnaire.

Background Information Questionnaire - BIQ was designed to gather information about teachers' gender, age, major of study, participation in TTC or teaching/testing workshops, teaching experience, hours of teaching per week, levels of their students (basic, intermediate, advance), and average number of students in their classes. In addition, it was mentioned that the study was conducted to investigate differences between assessment methods used in adult and young adult learners' classes, and teachers should consider just one group to fill out the assessment questionnaire. The language of BIQ was English.

Assessment questionnaire - Assessment questionnaire was designed according to Cheng et al.'s (2004) study. Cheng et al. listed the methods of assessing listening, speaking, reading, and writing by the help of 
Methods of assessing reading used by Iranian EFL teachers

different studies and books. In the present study, these methods were organized based on Brown's (2004) classification of different types of reading. A 5-point Likert scale was provided for this part of the questionnaire. Assessment questionnaire was written in English, since it was concluded that teachers were more familiar with English names of assessment methods after conducting the pilot study. Nine methods of assessing reading were listed. Additionally, a separate part was provided for teacher-made tests which consisted of six items. The categorization of reading assessment methods is shown in Table 1.

\section{Table 1}

Categorization of reading tasks in the study

\begin{tabular}{lll}
\hline 1 & $\begin{array}{l}\text { Perceptive tasks } \\
\text { Literacy tasks done at the beginning level of reading. }\end{array}$ & Reading aloud \\
\hline 2 & Interactive tasks & Oral questioning \\
& Tasks in which the learner interacts with the text. & \\
\hline 3 & $\begin{array}{l}\text { Extensive tasks } \\
\text { Reading long texts to understand the meaning of the whole text (top-down } \\
\text { processing) }\end{array}$ & \\
\hline 4 & Alternatives in assessment & Summaries of what is read \\
& & Student journal \\
& & Peer-assessment \\
& & Self-assessment \\
\hline & Teacher-made tests & Multiple-choice tests \\
& Paper-and-pencil tests designed, administered, and scored by teachers & True-false items \\
& Matching items \\
& & Short answer items \\
\hline 6 & Standardized reading tests & Cloze tests \\
\hline
\end{tabular}

\subsection{Participants}

Simple random sampling was used to choose ten private English institutes (in Isfahan), however accidental sampling was employed to select the individuals since some teachers did not cooperate. All in all, 200 teachers filled out the questionnaires, but 50 questionnaires were filled our incorrectly. So, 150 questionnaires were considered as data. Half of the teachers were teaching to young adults (12 to 18-years-old learners) and the other half were teaching to adults (18 to 30-years-old learners). Their teaching experience, number of classes per week, and average number of learners in each class are shown in Table 2.

Table 2

Characteristics of teacher participants in the survey (part 1)

\begin{tabular}{lcccc}
\hline \multicolumn{1}{c}{ Characteristics of teachers } & Min. & Max. & Mean & N \\
\hline Age & 20.00 & 53.00 & 27 & 150 \\
\hline Teachers of adult learners & 22 & 50 & 27.5 & 75 \\
Teachers of young adult learners & 20 & 53 & 27 & 75 \\
\hline Years of teaching Experience & 1.00 & 17.00 & 5.2 & 150 \\
\hline Teachers of adult learners & 1 & 17 & 6 & 75 \\
Teachers of young adult learners & 1 & 16 & 4.4 & 75 \\
\hline Number of classes in a week & 1.00 & 15.00 & 4.9 & 150 \\
\hline Teachers of adult learners & 1 & 14 & 5.1 & 75 \\
Teachers of young adult learners & 1 & 15 & 4.7 & 75 \\
\hline Average number of students in one class & 4.00 & 30.00 & 12.3 & 150 \\
\hline Teachers of adult learners & 4 & 30 & 11.6 & 75 \\
Teachers of young adult learners & 4 & 30 & 13 & 75 \\
\hline
\end{tabular}


Ketabi, S.

Most of the participants in this study were female and hold MA on one of the majors of TEFL (teaching English as a foreign language), translation studies, or English literature. Moreover, teachers were mostly teaching to intermediate or advanced students at the time of collecting the data. Among 150 teachers, 26 teachers had not participated in a TTC (teacher training course) or a teaching/testing workshop. Table 3 provides a better image of participants.

Table 3

Characteristics of teacher participants in the survey (part 2)

\begin{tabular}{|c|c|c|c|c|c|c|}
\hline \multirow{2}{*}{ Characteristics of teachers } & \multicolumn{2}{|c|}{ Adults } & \multicolumn{2}{|c|}{ Young adults } & \multicolumn{2}{|c|}{ Total } \\
\hline & $\mathrm{N}$ & $\%$ & $\mathrm{~N}$ & $\%$ & $\mathrm{~N}$ & $\%$ \\
\hline \multicolumn{7}{|l|}{ Gender } \\
\hline Female & 48 & 64 & 53 & 70.7 & 101 & 67.3 \\
\hline Male & 27 & 36 & 22 & 29.3 & 49 & 32.7 \\
\hline \multicolumn{7}{|l|}{ Educational degree } \\
\hline BA & 24 & 32 & 30 & 40 & 54 & 36 \\
\hline MA & 47 & 62.7 & 45 & 60 & 92 & 61.3 \\
\hline $\mathrm{PhD}$ & 4 & 5.3 & 0 & 0 & 4 & 2.7 \\
\hline \multicolumn{7}{|l|}{ Level of the students } \\
\hline Beginners & 11 & 14.7 & 31 & 41.3 & 42 & 28 \\
\hline Intermediate & 32 & 42.7 & 40 & 53.3 & 72 & 48 \\
\hline Advance & 32 & 42.7 & 4 & 5.3 & 36 & 24 \\
\hline \multicolumn{7}{|c|}{ Participation in teacher training course or workshop } \\
\hline Yes & 64 & 85.3 & 60 & 80 & 124 & 82.7 \\
\hline No & 11 & 14.7 & 15 & 20 & 26 & 17.3 \\
\hline \multicolumn{7}{|c|}{ Participation in language assessment course or workshop } \\
\hline $\begin{array}{l}\text { Yes } \\
\text { No }\end{array}$ & 61 & 81.3 & 66 & 88 & 127 & 84.7 \\
\hline No & 14 & 18.7 & 9 & 12 & 23 & 15.3 \\
\hline
\end{tabular}

\subsection{Pilot study}

The main objectives of conducting pilot study was estimating validity and reliability of the questionnaire, detecting vague or confusing items, selecting the appropriate language of each part, and the time needed to fill out the questionnaire. According to teachers' comments, 4-6 minutes were enough to fill out the questionnaire. Cronbach's alpha of the assessment questionnaire was 0.905 .

\subsection{Data analysis procedure}

Total scores of the items were calculated by adding the numbers teachers chose for them. The numbers showed how often one method was used $(0=$ never, $1=$ rarely, $2=$ sometimes, $3=$ often, $4=$ always $)$. Since the scale was ordinal, non-parametric statistics was employed to compare the popularity of methods among teachers of adult and young adult learners. Chi-square test was chosen to see whether a significant difference existed between two groups.

\section{Data Analysis and Results}

\subsection{Popularity of different methods to assess reading}

The first research question was formulated to investigate about different reading assessment methods used 
Methods of assessing reading used by Iranian EFL teachers

by Iranian teachers. Item scores were calculated to understand which methods were the most popular. Average score was calculated for categories containing two or more methods. Table 4 summarizes the results of this part of the study.

Table 4

Total scores for different methods of reading assessment

\begin{tabular}{|c|c|c|}
\hline & Categories of reading assessment methods & $\begin{array}{c}\text { Scores of each category used by teachers } \\
\text { of adultlyoung adult learners }\end{array}$ \\
\hline 1 & $\begin{array}{l}\text { Perceptive tasks } \\
\text { Reading aloud }\end{array}$ & $290 \backslash 318$ \\
\hline 2 & $\begin{array}{l}\text { Interactive tasks } \\
\text { Oral questioning }\end{array}$ & $210 \backslash 191$ \\
\hline 3 & $\begin{array}{l}\text { Extensive tasks } \\
\text { Summaries of what is read }\end{array}$ & $234 \backslash 215$ \\
\hline 4 & $\begin{array}{l}\text { Alternative assessment tasks } \\
\text { Student journal } \\
\text { Student portfolio } \\
\text { Peer-assessment } \\
\text { Self-assessment }\end{array}$ & $118 \backslash 136$ \\
\hline 5 & Teacher-made tests & $204 \backslash 195$ \\
\hline 6 & Standardized reading tests & $221 \backslash 239$ \\
\hline
\end{tabular}

According to total scores, the most popular methods of assessing reading were perceptive tasks in both groups of teachers. Extensive tasks and standardized reading tests were also common among teachers of adult and young adult learners. Alternative assessment methods were reported to be the least popular tasks among teachers of both groups.

Perceptive reading tasks - The most popular task to assess reading among teachers of both groups was reading aloud. It should be mentioned that teachers of young adult learners used this method significantly more than teachers of adult learners as the significance level is below 0.05 (Asymp. Sig. = .025). About 80 percent of teachers of young adults always or often employed this method to assess reading, whereas 66 percent of teachers of adult learners did so. Table 5 shows the frequency of reading aloud method.

Table 5

Frequency and percentage of reading task in adult/young adult classes

\begin{tabular}{|c|c|c|c|c|c|c|c|c|}
\hline \multirow[b]{2}{*}{$\begin{array}{l}\text { Perceptive } \\
\text { reading task }\end{array}$} & & \multicolumn{6}{|c|}{ Adults'lyoung adults' teachers } & \multirow{2}{*}{ 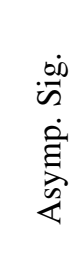 } \\
\hline & & $\frac{\dot{0}}{\grave{z}}$ & 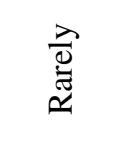 & 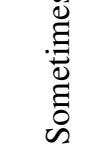 & $\underbrace{ \pm ๊}_{0}$ & 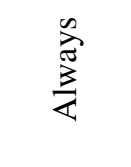 & $\begin{array}{c}\text { Total } \\
\text { score of } \\
\text { the item }\end{array}$ & \\
\hline \multirow{2}{*}{ Reading aloud } & $\mathrm{N}$ & 315 & $7 \backslash 4$ & $17 \backslash 6$ & $18 \backslash 13$ & $30 \backslash 47$ & \multirow{2}{*}{$290 \backslash 318$} & \multirow{2}{*}{$.025^{*}$} \\
\hline & $\%$ & $4 \backslash 6.7$ & $9.3 \backslash 5.3$ & $22.7 \backslash 8$ & $24 \backslash 17.3$ & $40 \backslash 62.7$ & & \\
\hline
\end{tabular}

No. of teachers in each group: 75

Interactive reading tasks - Less than half of the teachers of adult learners (41.4 percent) and about 36 percent of teachers of young adult learners always or often employed oral questioning to assess reading. As it is shown in Table 6, no significant difference was observed between teachers of both groups as Asymp. Sig. is more than 0.05. Moreover, oral questioning was not a popular task to assess reading as about half of the teachers of adult and young adult learners rarely or never made use of this method. 
Ketabi, S.

Table 6

Frequency and percentage of interactive reading task in adult/young adult classes

\begin{tabular}{|c|c|c|c|c|c|c|c|c|}
\hline \multirow[b]{2}{*}{$\begin{array}{l}\text { Interactive } \\
\text { reading task }\end{array}$} & & \multicolumn{6}{|c|}{ Adults'lyoung adults' teachers } & \multirow[b]{2}{*}{$\begin{array}{l}\dot{\infty} \\
\dot{n} \\
\dot{0} \\
\dot{0} \\
\frac{\pi}{2}\end{array}$} \\
\hline & & $\begin{array}{l}\overline{0} \\
\overrightarrow{0} \\
\bar{z}\end{array}$ & 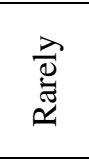 & 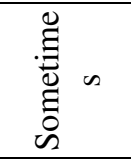 & 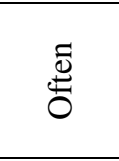 & $\sum_{i}^{\infty}$ & $\begin{array}{c}\text { Total } \\
\text { score of } \\
\text { the item }\end{array}$ & \\
\hline \multirow{2}{*}{ Oral questioning } & $\mathrm{N}$ & $32 \backslash 38$ & $2 \backslash 3$ & $10 \backslash 7$ & $11 \backslash 9$ & $20 \backslash 18$ & \multirow{2}{*}{$210 \backslash 191$} & \multirow{2}{*}{.818} \\
\hline & $\%$ & $42.7 \backslash 50.7$ & $2.7 \backslash 4$ & $13.3 \backslash 9.3$ & $14.7 \backslash 12$ & $26.7 \backslash 24$ & & \\
\hline
\end{tabular}

No. of teachers in each group: 75

Extensive reading tasks - Preparing summaries of what is read is an example of extensive reading task which was listed in the questionnaire of this study. Table 7 shows the status of the method among teachers of adult and young adult learners. This task of assessing reading was ranked $2^{\text {nd }}$ and $3^{\text {rd }}$ based on the report of teachers of adult and young adult learners respectively. About half of the teachers in adult learners' classes always or often employed this method, whereas 42 percent of teachers of young adult learners did so. The significance level is more than 0.05 , so there was no significant difference in employing this method between teachers of two groups.

Table 7

Frequency and percentage of extensive reading task in adult/young adult classes

\begin{tabular}{|c|c|c|c|c|c|c|c|c|}
\hline \multirow[b]{2}{*}{$\begin{array}{l}\text { Extensive } \\
\text { reading task }\end{array}$} & & \multicolumn{6}{|c|}{ Adults'lyoung adults' teachers } & \multirow[b]{2}{*}{ 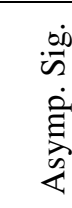 } \\
\hline & & $\begin{array}{l}\dot{D} \\
\dot{0} \\
\bar{z}\end{array}$ & 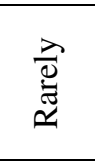 & 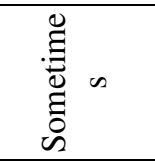 & $\underbrace{\frac{ \pm}{0}}_{0}$ & $\sum_{\frac{1}{2}}^{\infty}$ & $\begin{array}{c}\text { Total } \\
\text { score of } \\
\text { the item }\end{array}$ & \\
\hline \multirow{2}{*}{$\begin{array}{l}\text { Students' summaries of } \\
\text { what is read }\end{array}$} & $\mathrm{N}$ & $24 \backslash 29$ & $2 \backslash 3$ & $8 \backslash 11$ & $23 \backslash 13$ & $18 \backslash 19$ & \multirow{2}{*}{$234 \backslash 215$} & \multirow{2}{*}{.413} \\
\hline & $\%$ & $32 \backslash 38.7$ & $2.7 \backslash 4$ & $10.7 \backslash 14.7$ & $30.7 \backslash 17.3$ & $24 \backslash 25.3$ & & \\
\hline
\end{tabular}

No. of teachers in each group: 75

Alternative assessment reading tasks - Examples of alternative assessment tasks in the questionnaire of this study were students' portfolios, journals, self-assessment, and peer-assessment. It should be said that most of teachers did not know about these methods and asked about them while filling out the questionnaire. This can partly explain the infrequent use of alternative methods of assessment. More than 70 percent of teachers in each group of teachers never or rarely made use of alternative assessment methods to assess the reading skill. In fact, alternatives in assessment were the least popular methods of assessing reading among teachers in both groups. These methods were more popular among teachers of young adult learners as the total scores indicated, but, as it can be seen in Table 8 , the difference is not significance.

Teacher-made reading tests - Teacher-made tests were ranked $5^{\text {th }}$ and $4^{\text {th }}$ in two groups of adult and young adult learners' teachers in turn. Fifty-four teachers of adult learners and 58 teachers of young adult learners rarely, sometimes, often, or always employed teacher-made tests to assess reading skills of their students. However, about one fourth of teachers in both groups often or always made use of teacher-made tests to assess reading. Among teacher-made tests, multiple-choice and true-false items were the most common items. About two third of teachers in adult and young adult learners' classes always or often employed multiple-choice items. As for true-false items, about 60 percent of teachers in both groups reported that they often or always used this type of items. The least reported item in both groups was sentence completion items, for about 77 percent of adult learners' teachers and 63 percent of young adult learners' teachers never or rarely used this method. Significance levels for teacher-made tests and types of teacher-made tests were not below 0.05, so teachers of adult and young adult learners did not differ significantly in using these methods of assessing reading. Table 9 shows the frequency of teacher-made items. 


\section{Table 8}

Frequency and percentage of alternative assessment reading tasks in adult/young adult classes

\begin{tabular}{|c|c|c|c|c|c|c|c|c|}
\hline \multirow[b]{2}{*}{$\begin{array}{l}\text { Alternative assessment } \\
\text { tasks }\end{array}$} & & \multicolumn{6}{|c|}{ Adults'lyoung adults' teachers } & \multirow[b]{2}{*}{ 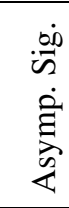 } \\
\hline & & $\begin{array}{l}\overline{0} \\
\vec{u}\end{array}$ & 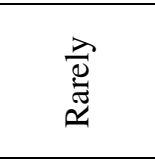 & 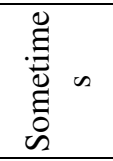 & $\underbrace{\mathbb{0}}_{0}$ & $\sum_{\frac{\pi}{2}}^{\infty}$ & $\begin{array}{c}\text { Total } \\
\text { score of } \\
\text { the item }\end{array}$ & \\
\hline \multirow{2}{*}{ Student journal } & $\mathrm{N}$ & $64 \backslash 59$ & $5 \backslash 3$ & $4 \backslash 5$ & $1 \backslash 6$ & 112 & \multirow{2}{*}{$95 \backslash 114$} & \multirow{2}{*}{.317} \\
\hline & $\%$ & 85.3178 .7 & $6.7 \backslash 4$ & $5.3 \backslash 6.7$ & $1.3 \backslash 8$ & $1.3 \backslash 2.7$ & & \\
\hline \multirow{2}{*}{ Student portfolio } & $\mathrm{N}$ & $64 \backslash 57$ & $5 \backslash 7$ & $4 \backslash 6$ & $1 \backslash 5$ & $1 \backslash 0$ & \multirow{2}{*}{$95 \backslash 109$} & \multirow{2}{*}{.308} \\
\hline & $\%$ & 85.3176 & $6.7 \backslash 9.3$ & $5.3 \backslash 8$ & $1.3 \backslash 6.7$ & $1.3 \backslash 0$ & & \\
\hline \multirow{2}{*}{ Peer assessment } & $\mathrm{N}$ & $49 \backslash 41$ & $8 \backslash 11$ & $7 \backslash 6$ & $9 \backslash 8$ & 219 & \multirow{2}{*}{$120 \backslash 127$} & \multirow{2}{*}{.689} \\
\hline & $\%$ & $65.3 \backslash 54.7$ & $10.7 \backslash 14.7$ & $9.3 \backslash 8$ & $12 \backslash 10.7$ & $2.7 \backslash 12$ & & \\
\hline \multirow{2}{*}{ Self-assessment } & $\mathrm{N}$ & $50 \backslash 45$ & $10 \backslash 11$ & $5 \backslash 6$ & $8 \backslash 9$ & $2 \backslash 4$ & \multirow{2}{*}{$127 \backslash 141$} & \multirow{2}{*}{.145} \\
\hline & $\%$ & $66.6 \backslash 60$ & $13.3 \backslash 14.6$ & 6.6618 & $10.6 \backslash 12$ & $2.6 \backslash 5.33$ & & \\
\hline
\end{tabular}

No. of teachers in each group: 75

\section{Table 9}

Frequency and percentage of different types of teacher-made tests in adult/young adult classes

\begin{tabular}{|c|c|c|c|c|c|c|c|c|}
\hline \multirow[b]{2}{*}{$\begin{array}{l}\text { Teacher-made tests for } \\
\text { reading assessment }\end{array}$} & \multicolumn{7}{|c|}{ Adults'lyoung adults' teachers } & \multirow[b]{2}{*}{$\begin{array}{l}\dot{\infty} \\
\dot{5} \\
\dot{0} \\
\frac{\hat{\sigma}}{4}\end{array}$} \\
\hline & $\mathrm{N}$ & $\begin{array}{l}\dot{D} \\
\dot{0} \\
z\end{array}$ & 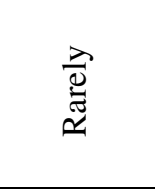 & 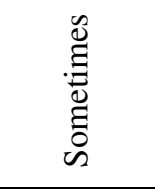 & 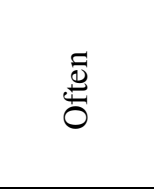 & $\sum_{\substack{2 \\
\sum}}^{\infty}$ & $\begin{array}{c}\text { Total } \\
\text { score of } \\
\text { the item }\end{array}$ & \\
\hline \multirow{2}{*}{ Teacher-made tests } & $75 \backslash 75$ & $21 \backslash 17$ & $9 \backslash 22$ & $24 \backslash 17$ & $12 \backslash 12$ & $9 \backslash 7$ & \multirow{2}{*}{$204 \backslash 195$} & \multirow{2}{*}{.120} \\
\hline & $\%$ & 28122.7 & $12 \backslash 29.3$ & $32 \backslash 22.7$ & $16 \backslash 16$ & $12 \backslash 9.3$ & & \\
\hline \multirow{2}{*}{ Multiple-choice tests } & $54 \backslash 58$ & $7 \backslash 9$ & $1 \backslash 5$ & $10 \backslash 8$ & 1619 & $20 \backslash 27$ & \multirow{2}{*}{$203 \backslash 214$} & \multirow{2}{*}{.199} \\
\hline & $\%$ & $13 \backslash 15.5$ & $1.9 \backslash 8.6$ & $18.5 \backslash 13.8$ & $29.6 \backslash 15.5$ & $37 \backslash 46.55$ & & \\
\hline \multirow{2}{*}{ Cloze tests } & $54 \backslash 58$ & $13 \backslash 25$ & $5 \backslash 7$ & $11 \backslash 3$ & $15 \backslash 11$ & $10 \backslash 12$ & \multirow{2}{*}{$166 \backslash 152$} & \multirow{2}{*}{.053} \\
\hline & $\%$ & $24.1 \backslash 43.1$ & $9.3 \backslash 12.1$ & $20.4 \backslash 5.2$ & $27.8 \backslash 19$ & $18.5 \backslash 20$ & & \\
\hline \multirow{2}{*}{ True-false items } & 54158 & $9 \backslash 12$ & $3 \backslash 4$ & $11 \backslash 7$ & 1618 & $16 \backslash 27$ & \multirow{2}{*}{$188 \backslash 208$} & \multirow{2}{*}{.180} \\
\hline & $\%$ & $16.7 \backslash 20.7$ & 5.616 .9 & $20.4 \backslash 12.1$ & $29.6 \backslash 13.8$ & 29.6146 .6 & & \\
\hline \multirow{2}{*}{ Matching items } & $54 \backslash 58$ & $17 \backslash 21$ & $7 \backslash 3$ & 1219 & $9 \backslash 4$ & $9 \backslash 21$ & \multirow{2}{*}{$148 \backslash 175$} & \multirow{2}{*}{.060} \\
\hline & $\%$ & $31.5 \backslash 36.2$ & $13 \backslash 5.2$ & $22.2 \backslash 15.5$ & $16.7 \backslash 6.9$ & $16.7 \backslash 36.2$ & & \\
\hline \multirow{2}{*}{ Short answer items } & $54 \backslash 58$ & $18 \backslash 25$ & $8 \backslash 5$ & $8 \backslash 5$ & $12 \backslash 7$ & $8 \backslash 16$ & \multirow{2}{*}{$146 \backslash 158$} & \multirow{2}{*}{.173} \\
\hline & $\%$ & $33.3 \backslash 43.1$ & $14.8 \backslash 8.6$ & $14.8 \backslash 8.6$ & $22.2 \backslash 12.1$ & $14.8 \backslash 27.6$ & & \\
\hline \multirow{2}{*}{$\begin{array}{l}\text { Sentence } \\
\text { completion items }\end{array}$} & $54 \backslash 58$ & $34 \backslash 30$ & 817 & $5 \backslash 8$ & $3 \backslash 5$ & 418 & \multirow{2}{*}{$97 \backslash 128$} & \multirow{2}{*}{609} \\
\hline & $\%$ & $63 \backslash 51.7$ & $14.8 \backslash 12.1$ & $9.3 \backslash 13.8$ & 5.618 .6 & $7.4 \backslash 3.8$ & & \\
\hline
\end{tabular}

Standardized reading tests - Standardized reading tests were reported to be the third and the second most popular methods to assess reading among teachers of adult and young adult learners respectively. Teachers of young adult learners were more inclined to use this method to assess reading than teachers of adult learners were; however, this difference is not significant as Asymp. Sig. in Table 10 indicates. 
Ketabi, S.

Table 10

Frequency and percentage of standardized reading tests in adult/young adult classes

Adults'lyoung adults' teachers

\begin{tabular}{|c|c|c|c|c|c|c|c|c|}
\hline & & & & & & & & \\
\hline $\begin{array}{l}\text { Standardized } \\
\text { reading tests }\end{array}$ & & $\begin{array}{l}\dot{0} \\
\stackrel{0}{0} \\
z\end{array}$ & 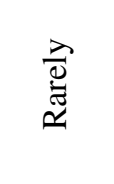 & 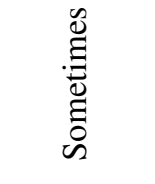 & 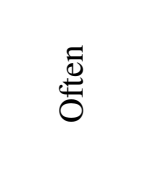 & $\sum_{i}^{\infty}$ & $\begin{array}{l}\text { Total score } \\
\text { of the item }\end{array}$ & 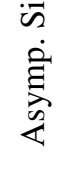 \\
\hline Standardized & $\mathrm{N}$ & $19 \backslash 22$ & $9 \backslash 5$ & $17 \backslash 11$ & $17 \backslash 11$ & $13 \backslash 26$ & 20 & 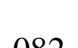 \\
\hline reading tests & $\%$ & $25.3 \backslash 29.3$ & $12 \backslash 6.7$ & $22.7 \backslash 14.7$ & $22.7 \backslash 14.7$ & $17.3 \backslash 34.7$ & 2211239 & .082 \\
\hline
\end{tabular}

No. of teachers in each group: 75

Among methods of assessing reading which were listed in the questionnaire of this survey, just one method - i.e. reading aloud - was reported to be always or often used by more than 50 percent of teachers in both groups. In contrast to the high popularity of the perceptive task of reading aloud, other reading tasks were considerably infrequently employed as reported by teachers of adult and young adult learners. Moreover, alternative assessment reading tasks were the least common tasks among teachers of both groups. Teachers of two groups did not differ significantly in favoring other methods of assessing reading.

\subsection{Differences in the methods used by teachers of adult and young adult learners}

Significant difference in the popularity of different methods of assessing reading was just found in perceptive task of reading aloud. Reading aloud was reported to be significantly more common among teachers of young adult learners.

\section{Discussion and conclusion}

The present study aimed at investigating different methods of assessing reading used by teachers of adult and young adult learners in Iran and also comparing the popularity of these methods in two groups of teachers of adult and young adult learners.

Receptive method of reading aloud was the most popular task among Iranian teachers of adult and young adult learners. More than 60 percent of teachers in both groups reported that they often or always employed this method. In comparison with reading aloud other methods received far less attention. Therefore, it can be concluded that Iranian teachers did not use a variety of methods to assess reading. Extensive and interactive tasks of preparing summaries and oral questioning were less common than reading aloud. Alternative assessment tasks, portfolios and journals, were the least popular tasks among teachers of both groups. A question can be asked here: Does this much use of receptive task and negligence on alternative assessment have any destructive effect on improving students' reading skill? As Brown (2004) stated, using different sources of information could be useful, and using one method instead of a variety of methods could not help in building students' proficiency. Reading aloud can be helpful in improving students' literacy skills, but it does nothing with students' reading comprehension and top-down processing.

Talking about significant differences, one can say that reading aloud is employed significantly more by young adult learners' teachers. This considerable difference can be explained by the fact that young adult learners are mostly at the beginning level of reading a second language, so literacy tasks are more emphasized in their classes.

Unpopularity of alternative methods of assessment might be because of the fact that most of the teachers indicated that they did not know exactly what journals and portfolios were at the time of collecting the data. 
Methods of assessing reading used by Iranian EFL teachers

Moreover, as Atai and Nikuinezhad (2006) reported, most of the students were worried about work-overload and insufficient amount of time to complete the tasks in portfolios. These researchers claimed that the main reason of this worrisome was the fact that the students were accustomed to traditional methods of assessment in Iran and could not adapt to alternative methods of assessment. It can also be true about teachers in Iran, since as Brown (2004) stated, alternatives in assessment are not practical methods to assess the students. So, lack of knowledge about alternatives in assessment and insufficient amount of time can be possible reasons for the unpopularity of alternative methods of assessment among Iranian teachers.

Comparing the results with those of Cheng et al.'s (2004), the researchers found that reading aloud was also common among teachers in Beijing, but teachers in Hong Kong and Canada were not interested in this method. Moreover, Teachers in Hong Kong, Canada, and Beijing reported that they employed more varieties of methods than did Iranian teachers. Portfolios and journals (as reading tasks) were also more popular among teachers in Cheng et al.'s study.

Iranian EFL teachers were not interested in using their own tests to assess students' reading skill. Less than 50 percent of teachers were reported that they often or always made use of teacher-made tests. Teachers in both groups chose multiple-choice items as the most popular format. True-false items and cloze tests were also common among Iranian EFL teachers of adult and young adult learners. In Cheng et al.'s (2004) study, teachers in Beijing chose multiple-choice items as the most popular format of their tests. However, teachers in Canada and Hong Kong were reported to use short answer items more than other items.

Less than half of Iranian EFL teachers were reported that they often or always employed standardized tests to assess reading, so standardized reading tests were not common among Iranian teachers. This percentage was similar to the percentage of Canadian teachers who chose standardized reading tests in Cheng et al.'s (2004) study. Based on the results of Cheng et al.'s study, teachers in Hong Kong were the least and teachers in Beijing were the most interested teachers in using standardized tests.

\section{References}

Akhondi, M., \& Aziz Malayeri, F. (2011). Assessing reading comprehension of expository texts across different response formats. Iranian Journal of Applied Language Studies, 3(1), 1-26.

Alderson, J. C. (2005). Diagnosing foreign language proficiency: The interface between learning and assessment. London: Continuum.

Alderson, J. C., Clapham, C., \& Wall, D. (1995). Language test construction and evaluation. Cambridge: Cambridge University Press.

Atai, M. R., \& Nikuinezhad, F. (2006). The effect of portfolio assessment on metacognitive reading strategy awareness of Iranian EFL students. Iranian Journal of Applied Linguistics, 9(2), 1-26.

Bernhardt, E. (1991). Reading development in a second language. New Jersey: Ablex.

Brown, H. D. (2004). Language assessment: principles and classroom practices. New York: Pearson Education.

Brown, J. D., \& Hudson, T. (1998). The alternatives in language assessment. TESOL Quarterly, 32, 653-675. http://dx.doi.org/10.2307/3587999

Cheng, L., Rogers, T., \& Hu, H. (2004). ESL/EFL instructors' classroom assessment practices: purposes, methods, and procedures. Language Testing, 21(3), 360-389. http://dx.doi.org/10.1191/02655322041t288oa

Coles, M. (1998). Assessing reading: Changing practice. In M. Coles \& R. Jenkins (Eds.), Assessing reading 2: Changing practice in classrooms (pp. 1-8). New York: Routledge.

Day, R. R., \& Park, J. (2005). Developing reading comprehension questions. Reading in a foreign language, $17(1), 60-73$.

Ediger, A. (2000). Teaching children literacy skills in a second language. In M. Celce-Murcia (Ed.), Teaching English as a second or foreign language (3rd ed., pp. 153-169). New York: Heinle \& Heinle.

Genesee, F., \& Upsher, J. A. (1996).Classroom-based evaluation in second language education. Cambridge: 
Ketabi, S.

Cambridge University Press.

Gipps, C. (1995). Beyond testing: Towards a theory of educational assessment. London: Falmer Press.

Grabe, W. (1991). Current development in second language reading research. TESOL Quarterly, 25, 375-406. http://dx.doi.org/10.2307/3586977

Harris, M., \& McCann, P. (1994). Assessment (Handbook for the English classroom). Oxford: Heinemann Publishers.

Jalalifarahani, M., \& Ghovehnodoushan, M. (2013). A survey on the techniques of students' reading assessment by English teachers at university. Frontiers of Language and Teaching, 4, 1-7.

Oller, J. W. (1979). Language tests at school: A Pragmatic approach. London: Longman.

Shams, N., \& Tavakoli, M. (2014). The effect of peer, self, and traditional assessment on Iranian EFL learners' L2 reading comprehension. Journal of Applied Linguistics and Language Research, 1(1), 29-44. 